2014s-29

\title{
Adaptation to Climate Change: How does Heterogeneity in Adaptation Costs Affect Climate Coalitions?
}

Itziar Lazkano, Walid Marrouch, Bruno Nkuiya

Série Scientifique
Scientific Series

\author{
Montréal \\ Mai 2014
}

(C) 2014 Itziar Lazkano, Walid Marrouch, Bruno Nkuiya. Tous droits réservés. All rights reserved. Reproduction partielle permise avec citation du document source, incluant la notice (C)

Short sections may be quoted without explicit permission, if full credit, including (C) notice, is given to the source.
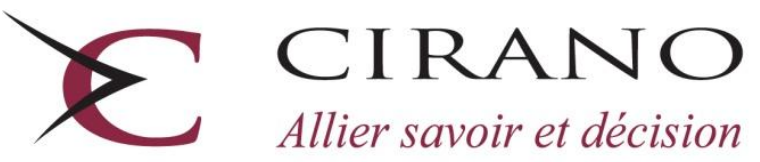

Allier savoir et décision

Centre interuniversitaire de recherche en analyse des organisations 


\section{CIRANO}

Le CIRANO est un organisme sans but lucratif constitué en vertu de la Loi des compagnies du Québec. Le financement de son infrastructure et de ses activités de recherche provient des cotisations de ses organisations-membres, d'une subvention d'infrastructure du Ministère de l'Enseignement supérieur, de la Recherche, de la Science et de la Technologie, de même que des subventions et mandats obtenus par ses équipes de recherche.

CIRANO is a private non-profit organization incorporated under the Québec Companies Act. Its infrastructure and research activities are funded through fees paid by member organizations, an infrastructure grant from the Ministère de l'Enseignement supérieur, de la Recherche, de la Science et de la Technologie, and grants and research mandates obtained by its research teams.

\section{Les partenaires du CIRANO}

\section{Partenaire majeur}

Ministère de l'Enseignement supérieur, de la Recherche, de la Science et de la Technologie

\section{Partenaires corporatifs}

Autorité des marchés financiers

Banque de développement du Canada

Banque du Canada

Banque Laurentienne du Canada

Banque Nationale du Canada

Banque Scotia

Bell Canada

BMO Groupe financier

Caisse de dépôt et placement du Québec

Fédération des caisses Desjardins du Québec

Financière Sun Life, Québec

Gaz Métro

Hydro-Québec

Industrie Canada

Intact

Investissements PSP

Ministère des Finances et de l'Économie

Power Corporation du Canada

Rio Tinto Alcan

Transat A.T.

Ville de Montréal

\section{Partenaires universitaires}

École Polytechnique de Montréal

École de technologie supérieure (ÉTS)

HEC Montréal

Institut national de la recherche scientifique (INRS)

McGill University

Université Concordia

Université de Montréal

Université de Sherbrooke

Université du Québec

Université du Québec à Montréal

Université Laval

Le CIRANO collabore avec de nombreux centres et chaires de recherche universitaires dont on peut consulter la liste sur son site web.

Les cahiers de la série scientifique (CS) visent à rendre accessibles des résultats de recherche effectuée au CIRANO afin de susciter échanges et commentaires. Ces cahiers sont écrits dans le style des publications scientifiques. Les idées et les opinions émises sont sous l'unique responsabilité des auteurs et ne représentent pas nécessairement les positions du CIRANO ou de ses partenaires.

This paper presents research carried out at CIRANO and aims at encouraging discussion and comment. The observations and viewpoints expressed are the sole responsibility of the authors. They do not necessarily represent positions of CIRANO or its partners. 


\title{
Adaptation to Climate Change: How does Heterogeneity in Adaptation Costs Affect Climate Coalitions?*
}

\author{
Itziar Lazkano ${ }^{\dagger}$, Walid Marrouch ${ }^{\ddagger}$,Bruno Nkuiya ${ }^{\S}$
}

\begin{abstract}
Résumé/abstract
Nous examinons comment l'adaptation au changement climatique influence les incitations à ratifier les accords internationaux environnementaux. En particulier, nous nous intéressons à deux effets liés à l'adaptation sur les incitations à approuver les accords climatiques. Tout d'abord, nous examinons les effets de l'hétérogénéité des coûts d'adaptation à travers les pays. Deuxièmement, nous étudions le rôle $\mathrm{du}$ 《leakage » entre pays. Nos résultats indiquent que les incitations à ratifier restent inchangées même en présence de l'hétérogénéité dans les coûts d'adaptation quand il n'y a pas de "leakage ». Cependant, l'hétérogénéité entre pays peut accroitre les incitations à ratifier ces accords en présence du «leakage». Nos résultats soulignent que les politiques visant à réduire la différence des coûts d'adaptation et le «leakage» peuvent influencer le succès ou l'échec des accords internationaux environnementaux.
\end{abstract}

Mots clés : adaptation, accords environnementaux, différences de coût, « leakage ».

We examine how adaptation to climate change affects the incentives to ratify international environmental agreements (IEAs). In particular, we study the effects of two aspects on the incentives to join a coalition. First, we analyze cross-country differences in adaptation costs. Second, we investigate the role of carbon leakage. Wefind that the incentives to join IEAs remain unchanged with crosscountry differences in adaptation when there is no carbon leakage, while these cross-country differences may strengthen the incentives to join IEAs with leakages. Our results emphasize that policies directed at reducing cost differences and carbon leakage may also affect the success and failure of IEAs.

Key words: adaptation; environmental agreements; cost differences; carbon leakage

Codes JEL : Q50, Q54, C72

\footnotetext{
${ }^{*}$ We thank Hassan Benchekroun, Amrita Ray Chaudhuri, Matthew McGinty, Yutaro Sakai and participants at AERE 2013, CREE 2013, Calgary Inaugural Alumni Conference 2014, Montreal Natural Resource and Environmental Economics Workshop 2014 and Universit_e de Sherbrooke for invaluable comments. We also thank Sahar Milani for excellent research assistance.

${ }^{\dagger}$ Corresponding author: Department of Economics and SFS, University of Wisconsin-Milwaukee. P.O. Box 413, Bolton Hall, Room 840, Milwaukee, 53201, WI, USA. E-mail:lazkano@uwm.edu.

* Department of Economics, Lebanese American University, Lebanon and CIRANO, Canada. Email:walid.marrouch@lau.edu.lb

$\S$ Donald Bren School of Environmental Science \& Management, University of California, Santa Barbara, USA.E-mail:bnkuiya@bren.ucsb.edu.
} 


\section{Introduction}

The United Nations Conference on Climate Change in Cancún in 2010 (COP16) and in Durban in 2011 (COP17) adopted a new approach to design international environmental agreements (IEAs) compared to the previous Kyoto framework. The new emerging postKyoto framework combines efforts of emissions abatement to adaptation. While most agree that abatement and adaptation are the two main available options to tackle climate change, unfortunately the role of adaptation is largely ignored in the study of IEAs. ${ }^{1}$ In this paper, we focus on two aspects in the decision to join a coalition. First, we study how cross-country differences in adaptation costs affect the incentives to join an IEA. Second, we investigate the role of carbon leakage in the incentives to join a coalition.

Adaptation refers to any activity with a potential to reduce the damages from climate change. For example, the construction of dams, levees or dikes, changing the types of crops used in agriculture or improving storm predictions and their warnings (Parry, 2007). The World Bank estimates that an approximate $2^{\circ} \mathrm{C}$ increase in world temperatures by 2050 may require between $\$ 70$ - $\$ 100$ billion a year in adaptation costs from 2010 to $2050 .^{2}$ These adaptation costs differ widely across countries. For instance, empirical studies find evidence of cost differences between developed and developing countries. ${ }^{3}$ These cross-country differences yield new challenges in understanding a country's incentives to join climate coalitions.

In this paper, we ask three questions. First, how do cross-country differences in adaptation costs affect emissions? Second, how do cross-country differences in adaptation costs change the incentives to join IEAs? And finally, what is the role of carbon leakage, combined with adaptation, in the incentives to join IEAs? We address these questions within

\footnotetext{
${ }^{1}$ The two exceptions are Benchekroun et al. (2011) and Marrouch \& Ray Chaudhuri (2011).

${ }^{2}$ These findings are from "The Economics of Adaptation to Climate Change (EACC)" study in 2011 by the World Bank. They also find that this amount is comparable to the current annual foreign aid from developed to developing countries.

${ }^{3}$ Ibid.
} 
the framework of IEA membership games first introduced by Carraro \& Siniscalco (1993) and Barrett (1994). The main difference in our setup is that we explicitly model carbon leakage and the possibility of adaptation, in addition to emissions abatement, to reduce environmental damages.

We consider a world consisting of many countries, and we introduce three modeling features that differentiate our paper from previous work. First, countries can simultaneously choose emissions and adaptation levels. In our context, the most important feature that distinguishes emissions and adaptation decisions relates to their public and private good nature. While each country's emissions generate a private benefit, their implications have a global public bad nature. Note, however, the distinction from adaptation. While adaptation also generates a private benefit, its implications only benefit the individual country. Therefore, in our setting, a key feature is that emissions abatement has a public good nature while adaptation has a private good nature.

Second, we account for cross-country differences in adaptation costs. Specifically, there are two types of countries: countries with low and high adaptation costs. This feature addresses some of the concerns raised in the recent climatic negotiations in Cancún in 2010 (COP16) and in Durban in 2011 (COP17), where the importance of adaptation differences among developed and developing countries for environmental agreements was highlighted. For example, the Cancún Adaptation Fund, established in 2010, aims at reducing the technological gap that exists between developed (low cost) and developing (high cost) countries.

The third modeling feature that differentiates our work is that we explicitly account for carbon leakage. We do so by modeling a general damage function that includes both the linear and quadratic forms. We capture the lack of carbon leakage by assuming linear damages, and the presence of leakage by assuming quadratic damages.

We define a country's payoff as the difference between benefits from emissions and the sum of environmental damages and adaptation costs. Each country's production activities 
generate a global pollutant that benefits each country privately while simultaneously damaging all countries. A country can offset these damages by choosing individual adaptation levels. We capture the expenditure in adaptation with an increasing cost function. Then, countries simultaneously choose emission and adaptation levels to maximize their own payoff given others' strategies.

Within this context, we derive several results. We find that the incentives to join a coalition remain unchanged with cross-country differences in adaptation when there is no carbon leakage. However, these cross-country differences may enhance the incentives to join IEAs with leakages. These results imply that, with leakage, the existence of adaptation encourages coalition formation, especially when countries differ in adaptation costs. Hence, coalition formation is sensitive to adaptation strategies and to the existence of carbon leakage. These findings imply that policies directed at reducing the gap in adaptation costs, such as the Cancún adaptation fund, or policies directed at reducing carbon leakage, such as the Clean Development Mechanism, may also impact the success of IEAs.

Our paper closely relates to two main strands of the literature. First, there is a literature that studies the relationship between emissions abatement and adaptation in climate economics, but ignore IEAs. A main goal of this literature is to better understand the relationship between abatement and adaptation as decisions to tackle environmental damages. For example, Kane \& Shogren (2000) examine the optimal mix of the two measures in a one-country model while Onuma \& Arino (2011) investigate how innovation in adaptation technology by a developed country may affect a developing country through changes in abatement efforts by both countries. Some studies also analyze the $n$-country case. For example, Buob \& Stephan $(2008,2011)$ develop a multi-region model where countries choose abatement and adaptation non-cooperatively. ${ }^{4}$ Zehaie (2009) studies the importance of the

\footnotetext{
${ }^{4}$ Buob \& Stephan (2011) study the strategic interaction between emissions and adaptation in a noncooperative game between different regions, assuming that emissions and adaptation are perfect substitutes. In Buob \& Stephan (2008) they use a non-cooperative Nash game to analyze whether funding adaptation is
} 
timing between adaptation and emissions and Ebert \& Welsch (2012) study the interactions between emissions and adaptation in a two country model. Our paper differs from these works because we study the incentives to join IEAs in addition to the relationship between emissions abatement and adaptation.

The second strand of the literature is extensive and studies the incentives to join IEAs and the stability of those agreements. Finus (2003) provides an excellent review of this literature. ${ }^{5}$ These studies, however, ignore adaptation. Our paper contributes to this broader literature as it is among the first to study adaptation within the context of IEAs and by doing so, we can examine additional challenges to the success and failure of IEAs. We are only aware of two studies directly studying adaptation in the context of IEAs. Benchekroun et al. (2011) study the effect of an improvement in adaptation technology on free riding incentives while Marrouch \& Ray Chaudhuri (2011) focus on the impact of adaptation on the stable size of the coalition. Our paper differs from these two papers because we analyze cross-country differences in adaptation costs and the role of carbon leakage in addition to adaptation. By doing so, and in contrast to others, we can identify conditions under which adaptation encourages or discourages IEA formation in a rich setting.

The remainder of the paper unfolds as follows. In Section 2, we present a model with heterogeneous adaptation costs. In Section 3, we present the polar cases of non-cooperative and cooperative behaviors. In Section 4, we examine coalition formation and the stability of IEAs. Finally, Section 5 concludes.

incentive compatible in the sense that it stimulates abatement of emissions.

${ }^{5}$ See also Hoel \& Schneider (1997), Eyckmans \& Tulkens (2003), and Petrosjan \& Zaccour (2003), and more recently, Rubio \& Ulph (2006, 2007), McGinty (2007), de Zeeuw (2008), Breton et al. (2010) and Nkuiya (2012). 


\section{The Model}

We consider a world economy with $n$ countries. Countries emit a global pollutant as a result of their consumption and production activities. We denote $e_{i}$ as the emission level of country $i$ where $i \in N=\{1,2, \ldots, n\}$, and $E=\sum_{i=1}^{n} e_{i}$ are total emissions. While total emissions yield damages for every country, each country can offset the effects of pollution by investing in adaptation. We denote $a_{i}$ as the adaptation level of country $i$ where $i=1,2, \ldots n$. We think of $a_{i}$ as effective adaptation that reflects both the level of the adaptation effort and the efficiency of the adaptation technology. Emissions and adaptation are the two strategies a country chooses in our model. The key difference between emissions and adaptation lies in the public nature of pollution and the private nature of adaptation. ${ }^{6}$ While each country's emissions are a private decision, global pollution is a global public bad and hence, countries have incentives to free ride on emissions abatement. Instead, adaptation is a private decision with country-specific benefits and costs. The distinction between the public and the private nature of emissions and adaptation is key to understand each country's incentives to join environmental coalitions to reduce global emissions.

In this model, each country's welfare (i.e., payoff) consists of benefits, damages, and costs. Each country simultaneously chooses their emissions and adaptation levels to maximize their payoff. ${ }^{7}$ Benefits depend on each country's individual emissions since it is a by-product of production and consumption. Global pollution damages all countries while each has the option to reduce damages through adaptation. Finally, adaptation is costly for each country. Formally, we define country $i$ 's payoff as:

$$
W\left(e_{i}, a_{i}, E\right) \equiv B\left(e_{i}\right)-D\left(E, a_{i}\right)-C^{j}\left(a_{i}\right),
$$

\footnotetext{
${ }^{6}$ One might argue that adaptation could also have some sort of public nature. See, for example, Mendelsohn (2000) who distinguishes private and public adaptation, and shows that the level of private adaptation is efficient, while joint adaptation may be under-provided.

${ }^{7}$ Our approach draws from Zehaie (2009) and Ebert \& Welsch (2012) who find that the sequential (ex-post adaptation) and simultaneous games are equivalent when a country chooses emissions and adaptation.
} 
where $B\left(e_{i}\right)$ is benefits from emissions described in $(2), D\left(E, a_{i}\right)$ is damages from pollution defined in (3) and $C^{j}\left(a_{i}\right)$ is the cost of adaptation defined in (4).

First, we consider a benefit function that is identical across countries. Country $i$ 's benefit from polluting is:

$$
B\left(e_{i}\right) \equiv e_{i}\left(\alpha-\beta \frac{e_{i}}{2}\right)
$$

where $\alpha$ and $\beta$ are positive parameters. We necessarily have $0<e_{i}<\frac{\alpha}{\beta}$ to guarantee a non-negative marginal benefit and $0<E<n \frac{\alpha}{\beta}$ since all countries are identical. The concave functional form of this benefit function is convenient since it allows us to restrict the maximum level of benefits a country can obtain from emissions. All countries benefit equally from emissions. This assumption implies that all countries use the same production technology. ${ }^{8}$

Second, the damage function for country $i$ is:

$$
D\left(E, a_{i}\right) \equiv\left(\omega-a_{i}\right) \frac{E^{\eta}}{\eta}
$$

where $\omega>0$ is a damage parameter from total pollution. ${ }^{9}$ Parameter $\eta \geq 1$ captures the curvature of the damage function. This damage function allows us to consider a continuum of cases, including linear and quadratic damage functions. This is in contrast to others who consider either the linear or the quadratic case in the study of incentives to join IEAs. By accounting for the curvature of the damage function, we are able to study cases with and without carbon leakage in emissions among countries. Carbon leakage refers to the increase in emissions by one country as a response to another country's emission reduction. Our spec-

\footnotetext{
${ }^{8}$ One might argue that countries benefit differently from emissions. We abstract from such heterogeneity to better understand the role of carbon leakage and heterogeneity in adaptation costs in the standard IEA setting. One could easily extend our model to incorporate differences across countries in the benefit function.

${ }^{9}$ Some might argue that global pollution affects countries differently. We abstract from this effect without loss of generality to concentrate on the importance of heterogeneity in adaptation costs and its implications for the stability of IEAs.
} 
ification in equation (3) allows us to study carbon leakage because when $\eta=1$, the damage function is linear and there is no carbon leakage among countries. Instead, when the damage function is non-linear $(\eta>1)$, there exist carbon leakage among countries. The explicit consideration of the curvature of the damage function is a novel feature of our model. We highlight three characteristics from equation (3). First, the marginal damage from emissions, $\frac{\partial D\left(E, a_{i}\right)}{\partial e_{i}}=\frac{\partial D\left(E, a_{i}\right)}{\partial E}=\left(\omega-a_{i}\right) E^{\eta-1} \geq 0$, is decreasing in adaptation $a_{i}$. Second, a country's damage decreases in its level of adaptation, $\frac{\partial D\left(E, a_{i}\right)}{\partial a_{i}}=\frac{-E^{\eta}}{\eta} \leq 0$. Third, the marginal benefit from adaptation is increasing in total emissions, $\frac{\partial^{2} D\left(E, a_{i}\right)}{\partial a_{i} \partial E}=-E^{\eta-1} \leq 0$.

Third, the adaptation cost function for county $i$, of type $j$, features diminishing returns to scale and is increasing in the level of adaptation:

$$
C^{j}\left(a_{i}\right) \equiv \frac{c^{j}}{2} a_{i}^{2}, \quad j=H, L
$$

where $c^{j}$ is the cost of adaptation. A second novel feature of our model is that we consider cross-country differences in adaptation costs. There are two types of countries: high $(H)$ and low $(L)$ adaptation cost countries. While global emissions damage all countries equally, we include heterogeneous adaptation costs across countries. That is, we allow countries to be identical within each group but differ across groups in their adaptation cost. $n^{H}$ and $n^{L}$ denote the number of each type such that they add up to the total number of countries $n=n^{L}+n^{H}$.

In the next section we analyze and compare the polar cases where the decision to join an IEA is exogenous. The partial equilibrium analysis follows in section 4 where the decision to join a coalition is endogenous. 


\section{Polar cases}

This section presents the cooperative and non-cooperative emission strategies and in section 3.3, we compare our results to previous results in the IEA literature where adaptation is mainly ignored. In the subsequent sections, we denote subscripts $n$ and $c$ to represent the non-cooperative and cooperative equilibrium outcomes to simplify notation.

\subsection{Non-cooperative outcome}

Country $i$ simultaneously chooses its emission and adaptation levels to maximize its own payoff taking as given the emission and adaptation choices of all other countries. ${ }^{10}$ Formally, country $i$ solves

$$
\max _{\left\{e_{i}, a_{i}\right\}} W\left(e_{i}, a_{i}, E\right)
$$

where $W\left(e_{i}, a_{i}, E\right)$ is given in $(1)$.

The first-order conditions for emissions $\left(e_{i}\right)$ and adaptation $\left(a_{i}\right)$ are:

$$
\begin{aligned}
\alpha-\beta e_{n}^{j} & =\left(\omega-a_{n}^{j}\right)\left(E_{n}\right)^{\eta-1}, \quad j=L, H \\
\frac{\left(E_{n}\right)^{\eta}}{\eta} & =c^{j} a_{n}^{j}, \quad j=L, H .
\end{aligned}
$$

Condition (6) indicates that each country chooses its equilibrium emission level so as to equate its marginal benefit and its marginal damage from polluting. Condition (7) shows that at the equilibrium, the marginal benefit and the marginal cost of adaptation are equal.

\footnotetext{
${ }^{10}$ The question of timing is inapplicable in our setting since the sequential (ex-post adaptation) and simultaneous games are equivalent. Note that the irrelevance of timing between emissions and adaptation only holds when adaptation happens after emissions in the sequential game. If a country chooses to adapt before polluting, the irrelevance of timing no longer holds. In our paper, we abstract from the possibility that countries would choose to adapt before polluting, and therefore, the irrelevance of timing shown by Zehaie (2009) holds. Therefore, the results of our simultaneous game are equivalent to those of a sequential game where countries choose adaptation after emissions.
} 
Using conditions (6) and (7), we derive the best-response functions:

$$
\begin{aligned}
& e_{n}^{j}=\frac{1}{\beta}\left(\alpha-\left(\omega-a_{n}^{j}\right)\left(E_{n}\right)^{\eta-1}\right), \quad j=L, H \\
& a_{n}^{j}=\frac{\left(E_{n}\right)^{\eta}}{c^{j} \eta}, \quad j=L, H .
\end{aligned}
$$

Substituting (9) into (8) yields emission levels as a function of total emissions for both types of countries:

$$
\begin{aligned}
e_{n}^{L} & =\frac{1}{\beta}\left(\alpha+\frac{\left(E_{n}\right)^{2 \eta-1}}{\eta c^{L}}-\omega\left(E_{n}\right)^{\eta-1}\right) \\
e_{n}^{H} & =\frac{1}{\beta}\left(\alpha+\frac{\left(E_{n}\right)^{2 \eta-1}}{\eta c^{H}}-\omega\left(E_{n}\right)^{\eta-1}\right) .
\end{aligned}
$$

Using (10) and (11) and the fact that $E_{n}=n^{L} e_{n}^{L}+n^{H} e_{n}^{H}$, the level, $E_{n}$, that solves the following equation is the non-cooperative level of total emissions:

$$
\eta\left(\beta E_{n}-n \alpha\right)=\left(E_{n}\right)^{\eta-1}\left[-n \eta \omega+\left(\frac{n^{L}}{c^{L}}+\frac{n^{H}}{c^{H}}\right)\left(E_{n}\right)^{\eta}\right]
$$

This result allows us to fully characterize the emission and adaptation levels of the noncooperative equilibrium. Indeed, the total emission level $E_{n} \in(0, n \alpha / \beta)$ is the unique positive solution of (12). Also, given $E_{n}$, country emission and adaptation levels are given in (8) and (9). As expected, condition (9) suggests that countries with a low cost of adaptation choose to adapt more than countries with a high cost of adaptation. 


\section{$3.2 \quad$ Full cooperative outcome}

All countries choose their emission and adaptation levels under the full cooperation outcome to maximize their joint payoff. Formally:

$$
\max _{\left\{e_{i}, a_{i}\right\}_{i \in N}} \sum_{i=1}^{n} W\left(e_{i}, a_{i}, E\right)
$$

where $W\left(e_{i}, a_{i}, E\right)$ is given in (1).

The first-order conditions for emissions and adaptation are:

$$
\begin{aligned}
\alpha-\beta e_{c}^{j} & =\left(n \omega-n^{H} a_{c}^{H}-n^{L} a_{c}^{L}\right)\left(E_{c}\right)^{\eta-1}, \quad j=L, H, \\
\frac{\left(E_{c}\right)^{\eta}}{\eta} & =c^{j} a_{c}^{j}, \quad j=L, H .
\end{aligned}
$$

The condition given by (14) indicates that when all countries cooperate, the marginal benefit from emissions equals the sum of the marginal damages from polluting. Equation (14) is the Samuelson (1954) condition for the provision of public goods, which in this case is global environmental quality. Condition (15) states that the private marginal benefit and cost from adaptation are equal. From conditions (14) and (15), we derive the best-response functions:

$$
\begin{aligned}
& e_{c}^{j}=\frac{1}{\beta}\left[\alpha-\left(n \omega-n^{H} a_{c}^{H}-n^{L} a_{c}^{L}\right)\left(E_{c}\right)^{\eta-1}\right], \quad j=L, H, \\
& a_{c}^{j}=\frac{\left(E_{c}\right)^{\eta}}{\eta c^{j}}, \quad j=L, H .
\end{aligned}
$$

We substitute equation (17) into (16) and using $E_{c}=n^{L} e_{c}^{L}+n^{H} e_{c}^{H}$ we derive:

$$
\eta\left(\beta E_{c}-n \alpha\right)=n\left(E_{c}\right)^{\eta-1}\left[-n \eta \omega+\left(\frac{n^{L}}{c^{L}}+\frac{n^{H}}{c^{H}}\right)\left(E_{c}\right)^{\eta}\right] .
$$

These calculations allow us to fully characterize the emission and adaptation levels of 
the cooperative setting. For each cost type, since countries have the same marginal benefit and marginal damage from pollution, they emit at the same level, even if they differ in adaptation costs. Furthermore, they fully internalize the negative global externality. Both a low and high cost country's emission levels are given in (16), while the differences among countries arise in their adaptation. For both country types, adaptation levels are given in (17). As expected, low cost countries always adapt more than high cost countries since the marginal cost to adapt is larger for a high cost country. At the aggregate level, total emissions, $E_{c} \in(0, n \alpha / \beta)$, are the unique positive root of (18).

In the next section, we investigate the role of carbon leakage in two polar cases.

\subsection{The role of carbon leakage}

We first analyze the implications of carbon leakage. We consider two cases: linear and non-linear damages (equation (3)). Recall that in the absence of adaptation $\left(a_{i}=0\right.$ in (3)-(4)), we know from the IEA literature that there is no carbon leakage in emissions among countries when damages are linear $(\eta=1)$ because the best-response functions are orthogonal. With a non-linear damage function $(\eta>1)$, however, there is carbon leakage in emissions among countries since the best-response functions are downward slopping. From the best-response function in equation (16), we confirm that the existence (and lack) of carbon leakage remains as before even when we introduce adaptation into the IEA model

(i.e. for the linear case $\frac{\partial e_{i}}{\partial e_{-i}}>0$, and for the non-linear case $\frac{\partial e_{i}}{\partial e_{-i}}<0$ ). With a linear damage function and adaptation, there is no leakage since the best-response functions become upward slopping while with non-linear damages, there are leakages in emissions because their bestresponse function remain downward sloping (eqs. (8)-(9)).

We compare the polar cases (cooperative and non-cooperative) in three propositions. First, we examine the strategic relationship between emissions and adaptation from the optimality conditions in (8) and (9). 
Proposition 1. The strategic relationship between emissions and adaptation depends on the existence of carbon leakage. In absence of leakage, emissions and adaptation are strategic complements in equilibrium while with leakages, they can be either complements or substitutes.

Proof. We substitute $E_{n}$ from (9) into (8) and we then differentiate individual emissions with respect to adaptation:

$$
\frac{\partial e_{n}^{j}}{\partial a_{n}^{j}}=\frac{c^{j}\left(\omega-a_{n}^{j}\right)(1-\eta)+a_{n}^{j} \eta}{\beta\left(a_{n}^{j} c^{j} \eta\right)^{\frac{1}{\eta}}} .
$$

When damages are linear $(\eta=1)$, equation (19) is always positive. However, with non-linear damages $(\eta>1)$, the sign depends on the magnitude of adaptation, costs and damages. This relationship also holds for the cooperative case using equations (16) and (17).

The strategic complementarity between emissions and adaptation describes how the incentives to emit respond to the possibilities to adapt in each country. We find that the role of leakage is critical to understand this relationship. The lack of leakage means that a country emits more as a response to others' increase in emissions. In that case, a country's choice of adaptation and emission move in the same direction. Hence, a country's option to reduce the impact of global pollution on damages is to adapt more. Conversely, when other countries emit less, a country will react by emitting less and reducing so the need to adapt. This is, there is a strategic complementarity between emissions and adaptation under the no-leakage scenario. However, the presence of leakage means that a country increases its own emissions as a response to other's reduction of emissions since the best-response functions are downward sloping. In this case, the relationship between emissions and adaptation depends on their magnitudes, where these two variables could exhibit complementarity or substitutability.

Next, we compare total emissions in the two polar cases. We begin with the case of 
no leakage, $(\eta=1$ in equation (3)), and calculate total emissions for the non-cooperative and cooperative cases. First, solving equation (12), we obtain total emissions for the noncooperative case:

$$
E_{n}=\frac{n(\alpha-\omega)}{\beta-\left(\frac{n^{H}}{c^{H}}+\frac{n^{L}}{c^{L}}\right)} .
$$

Second, solving for (18), we obtain total emissions for the cooperative case:

$$
E_{c}=\frac{n(\alpha-n \omega)}{\beta-n\left(\frac{n^{H}}{c^{H}}+\frac{n^{L}}{c^{L}}\right)} .
$$

An interior solution where countries generate positive emission levels requires the following two conditions: ${ }^{11}$

$$
\begin{array}{r}
\alpha>n \omega, \\
\beta>n\left(\frac{n^{H}}{c^{H}}+\frac{n^{L}}{c^{L}}\right) .
\end{array}
$$

We compare total emissions in the two polar cases using equations (20) and (21). In the absence of adaptation, a global agreement to reduce pollution always leads to lower total emissions than the case with no agreement because countries internalize the negative externality of polluting. As expected, this result also holds with cost heterogeneity in adaptation. Proposition 2 summarizes this comparison.

Proposition 2. In the presence of adaptation and no carbon leakage, total emissions are lower under full cooperation than under non-cooperation in emissions abatement. Furthermore, countries adapt more under non-cooperation.

Proof. See the Appendix.

\footnotetext{
${ }^{11}$ We derive these two existence conditions substituting equation (12) into equation (10) and equation (21) into equation (16) in the linear case $(\eta=1)$.
} 
Next, we analyze the effects of carbon leakage in total emissions $(\eta>1$ in equation (3)).

Proposition 3. In the presence of adaptation and carbon leakage, total emissions are lower under full cooperation than under non-cooperation in emissions abatement. Furthermore, countries adapt more under non-cooperation.

Proof. See the Appendix.

This result is also consistent with the literature on transboundary pollution and holds because the marginal cost of emitting in the fully cooperative setting is larger than in the non-cooperative equilibrium. This is the case because the presence of adaptation does not change the negative sign of the slope of the best-response emissions function. As such, the disincentive to emit is larger under full cooperation. Following the same reasoning, with full cooperation, countries adapt less.

\section{Coalition formation and stability}

In this section, we examine the incentives to voluntarily join a coalition and the stability of such self-enforcing agreement. This IEA is a two-stage game. In the first stage (the membership game), countries decide unilaterally whether to ratify the treaty. In the second stage, signatory countries decide jointly the emission level that maximizes their aggregate payoff, while non-signatory countries choose the individual emissions to maximize their own payoff. Furthermore, every country chooses their own private adaptation level. Our game follows the Cournot approach when choosing emissions and adaptation. We solve this game by backward induction starting from the second stage.

We denote $k^{L}$ and $k^{H}$ as the number of low and high cost signatory countries. The total number of countries that join the IEA is $k=k^{L}+k^{H}$ while $n-k$ countries choose to stay out of the coalition. We first analyze the incentives to emit and adapt of non-signatory 
countries. A non-signatory country $i$ solves:

$$
\max _{\left\{e_{i}, a_{i}\right\}_{i \in N \backslash S}} W\left(e_{i}, a_{i}, E\right),
$$

where $N \backslash S$ is the set of non-signatory countries. From the first order conditions, we derive the best-response functions for emissions and adaptation:

$$
\begin{aligned}
& e_{n s}^{j}=\frac{1}{\beta}\left(\alpha-\left(\omega-a_{n s}^{j}\right) E^{\eta-1}\right), \quad j=L, H, \\
& a_{n s}^{j}=\frac{E^{\eta}}{\eta c^{j}}, \quad j=L, H,
\end{aligned}
$$

where the subscript $n s$ stands for non-signatory countries. Second, we derive the emission and adaptation strategies of signatory countries. Signatory countries solves:

$$
\max _{\left\{e_{i}, a_{i}\right\}_{i \in S}} \sum_{i \in S} W\left(E, a_{i}\right)
$$

where $S$ represents the set of signatory countries. The best-response functions of emissions and adaptation are:

$$
\begin{aligned}
e_{s}^{j} & =\frac{1}{\beta}\left(\alpha-\left(k \omega-k^{L} a_{s}^{L}-k^{H} a_{s}^{H}\right) E^{\eta-1}\right), \quad j=L, H, \\
a_{s}^{j} & =\frac{E^{\eta}}{\eta c^{j}}, \quad j=L, H,
\end{aligned}
$$

where $s$ stands for signatory countries.

Next, we calculate total emissions for non-signatory and signatory countries. Total emissions from non-signatories is $E_{n s}$. Using equation (25), combined with $E_{n s}=\left(n^{L}-k^{L}\right) e_{n s}^{L}+\left(n^{H}-k^{H}\right) e_{n s}^{H}$, we get:

$$
E_{n s}=\frac{1}{\beta}\left[(n-k) \alpha-\left((n-k) \omega-\frac{n^{L}-k^{L}}{\eta c^{L}} E^{\eta}-\frac{n^{H}-k^{H}}{\eta c^{H}} E^{\eta}\right) E^{\eta-1}\right] .
$$

Likewise, using equation (28) along with $E_{s}=k^{L} e_{s}^{L}+k^{H} e_{s}^{H}$, we obtain:

$$
E_{s}=\frac{1}{\beta}\left[k \alpha-\left(k^{2} \omega-\frac{k k^{L}}{\eta c^{L}} E^{\eta}-\frac{k k^{H}}{\eta c^{H}} E^{\eta}\right) E^{\eta-1}\right] \text {. }
$$


We calculate total emissions summing (30) and (31). After rearranging terms, we find that total emissions $(E)$ are the positive root of the equation:

$$
\eta(\beta E-n \alpha)=E^{\eta-1}\left[-\left(n-k+k^{2}\right) \eta \omega+\left(\frac{n^{L}+k^{L}(k-1)}{c^{L}}+\frac{n^{H}+k^{H}(k-1)}{c^{H}}\right) E^{\eta}\right] .
$$

Notice that for the polar cases, $k^{L}=k^{H}=0$ or $k^{L}+k^{H}=1$, equation (32) yields exactly relation (12), characterizing total emissions obtained under the non-cooperative equilibrium. For $k^{L}=n^{L}$ and $k^{H}=n^{H}$, (32) becomes (18), characterizing total emissions for the cooperative setting. The equilibrium level of total emissions $E \in(0, n \alpha / \beta)$ is a root of (32). Given this result, the adaptation levels of non-signatories and signatories are given in (26) and (29). Also, given adaptation, the emission level of a non-signatory and a signatory are given in (25) and (28). From these equations, we derive the following proposition.

Proposition 4. All signatory countries choose the same emission level while non-signatory countries emit according to their adaptation cost.

Proof. For signatories, equilibrium emissions in equation (28) are independent of the cost type. For non-signatories, however, equilibrium emissions in equation (25) depend on the adaptation cost type.

Our results in proposition 4 describe country incentives to emit for a given coalition size. We find that all countries within the agreement emit equally while countries outside of the coalition behave as singletons. The non-signatory countries act in their own self interest and emit according to their adaptation cost as in the pure non-cooperative case. We explore adaptation next.

Proposition 5. Adaptation in equilibrium is a dominant action and independent of a country's IEA membership decision.

Proof. From equilibrium outcomes in equations (26) and (29) for non-signatories and signatories, a country's adaptation level is determined by total emissions instead of its own 
individual emissions.

Countries choose their adaptation level independently of their IEA membership decision. Thus, high and low cost countries choose their emissions depending on their cost type. This result is driven by the private good nature of adaptation.

Proposition 6. The presence of adaptation does not nullify the emissions abating role of IEAs.

Proof. Using (25) and (28) along with the facts that $\omega \geq a_{s}^{j}$, and $\omega \geq a_{n s}^{j}$, we get

$$
e_{n s}^{j}-e_{s}^{j} \geq \omega(k-1)+a_{n s}^{j}+k \omega>0 .
$$

Therefore, a non-signatory country always emits more than a signatory country.

In line with the established IEA literature, this result describes that the presence of adaptation is not a limiting factor in the role of a climatic coalition. Some argue against placing efforts into adaptation, fearing diminished willingness to abate within environmental agreements. ${ }^{12}$ Contrary to this belief, our result shows that the presence of adaptation does not obstruct the success of IEAs at reducing emissions within a coalition.

\subsection{Stability conditions}

Next, we study the incentives to ratify an IEA. We follow the stability concept first introduced by d'Aspremont et al. (1983). A coalition is stable when both the internal and external stability conditions hold. Internal stability holds when no country inside of the coalition has incentives to leave the coalition while external stability holds when no country outside of the coalition has incentives to join the coalition. The internal stability conditions for low and

\footnotetext{
${ }^{12}$ See for example the article "Dutch defense against climate change: Adapt" published in The Washington Post in 2009.
} 
high cost countries are:

$$
\begin{aligned}
& W_{s}^{L}\left(k^{L}, k^{H}\right) \geq W_{n s}^{L}\left(k^{L}-1, k^{H}\right), \\
& W_{s}^{H}\left(k^{L}, k^{H}\right) \geq W_{n s}^{H}\left(k^{L}, k^{H}-1\right),
\end{aligned}
$$

and, the external stability conditions for low and high cost countries are:

$$
\begin{aligned}
& W_{n s}^{L}\left(k^{L}, k^{H}\right) \geq W_{s}^{L}\left(k^{L}+1, k^{H}\right), \\
& W_{n s}^{H}\left(k^{L}, k^{H}\right) \geq W_{s}^{H}\left(k^{L}, k^{H}+1\right) .
\end{aligned}
$$

We compute the incentives to deviate by comparing each country's payoffs. For a given coalition size, $k=k^{L}+k^{H}$, the net payoff of a signatory and a non-signatory of type $j$ are:

$$
\begin{aligned}
W_{s}^{j}\left(k^{L}, k^{H}\right) & =e_{s}^{j}\left(\alpha-\frac{\beta}{2} e_{s}^{j}\right)-\left(\omega-a_{s}^{j}\right) \frac{E^{\eta}}{\eta}-\frac{1}{2}\left(a_{s}^{j}\right)^{2}, \\
W_{n s}^{j}\left(k^{L}, k^{H}\right) & =e_{n s}^{j}\left(\alpha-\frac{\beta}{2} e_{n s}^{j}\right)-\left(\omega-a_{n s}^{j}\right) \frac{E^{\eta}}{\eta}-\frac{1}{2}\left(a_{n s}^{j}\right)^{2},
\end{aligned}
$$

where $e_{s}^{j}, e_{n s}^{j}, a_{s}^{j}, a_{n s}^{j}$, and $E$ are defined in equations (25), (26), (28), (29), and (32). Using this conditions along with $e_{n s}^{j}>e_{s}^{j}$ and $a_{n s}^{j}=a_{s}^{j}$, we compare the net payoff of countries with the same cost of adaptation inside and outside of the agreement. Comparing equations (37) and (38), we find that countries with low (high) adaptation cost who agree to join the coalition always gain less (more) than those countries of the same type who choose to stay out of the coalition. This comparison helps us understand the characteristics of countries with stronger incentives to join coalitions.

We summarize these stability conditions using a stability function for low and high cost countries following the approach by Hoel \& Schneider (1997) and Nkuiya et al. (2014): ${ }^{13}$

$$
\begin{aligned}
\phi^{L}\left(k^{L}, k^{H}\right) & =W_{s}^{L}\left(k^{L}, k^{H}\right)-W_{n s}^{L}\left(k^{L}-1, k^{H}\right), \\
\phi^{H}\left(k^{L}, k^{H}\right) & =W_{s}^{H}\left(k^{L}, k^{H}\right)-W_{n s}^{H}\left(k^{L}, k^{H}-1\right) .
\end{aligned}
$$

\footnotetext{
${ }^{13}$ Following the norm in this literature, we restrict our attention to the largest stable coalition size that arises.
} 
The coalition $\left(k^{L}, k^{H}\right)$ is internally stable when the conditions $\phi^{j}\left(k^{L}, k^{H}\right) \geq 0, j=L, H$ hold. And the coalition $\left(k^{L}, k^{H}\right)$ is externally stable when the conditions $\phi^{L}\left(k^{L}+1, k^{H}\right) \leq$ 0 , and $\phi^{L}\left(k^{L}, k^{H}+1\right) \leq 0$ hold.

\subsection{Stability analysis}

In this section, we seek to understand how adaptation changes the incentives to join an IEA. In particular, we focus on two aspects: the role of carbon leakage and the role of cost heterogeneity in adaptation costs. To explore these roles, we consider four cases. We first study coalition formation with identical and different adaptation costs in a world with no leakage. We then consider identical and different adaptation costs but in a world with carbon leakage. Our baseline scenario is the case where adaptation is not possible. Table 1 and proposition 7 summarize our results.

Table 1: Stable coalition size with adaptation, cost heterogeneity and leakage.

\begin{tabular}{|c|c|c|c|c|}
\hline & \multicolumn{2}{|c|}{ No leakage } & \multicolumn{2}{|c|}{ Leakage } \\
\hline & Identical costs & Different costs & Identical costs & Different costs \\
\hline No adaptation & \multicolumn{2}{|c|}{ "max 3 countries } & \multicolumn{2}{|c|}{ "max 2 countries } \\
\hline Adaptation & $\max 3$ countries & $\max 3$ countries & $\max 3$ countries & max grand coalition \\
\hline
\end{tabular}

In the first row of Table 1, we present the well-known results from the IEA literature with a Cournot set-up where adaptation is ignored. We do so to better understand how the incentives to join a coalition change in our setting. The previous literature shows that the maximum number of countries that join a stable coalitions is three in absence of leakage while the maximum number of countries is two with leakages (see, for example, Finus, 2003). In our paper, we derive the following results:

Proposition 7. Adaptation is unsuccessful at encouraging participation without leakages while potentially successful with leakages. Specifically: 
(i) A maximum of three countries form a stable coalition when all countries have identical adaptation costs and there are no leakages in emissions.

(ii) A maximum of three countries form a stable coalition when all countries differ in adaptation costs and there are no leakages in emissions.

(iii) A maximum of three countries form a stable coalition when all countries have identical adaptation costs and there are leakages in emissions.

(iv) Large stable coalitions can arise when countries differ in adaptation costs and there are leakages in emissions.

Proof. See the Appendix for the formal proof of (i). In the text we provide numerical examples to prove (ii), (iii) and (iv).

We first analyze coalition formation with no leakage and identical adaptation costs i.e., $c^{L}=c^{H}=c$. This case corresponds to the second row of Table 1 and Proposition 7.(i) (see the Appendix for the formal proof). We show that the option to adapt does not change the incentives to join a coalition compared to the case where adaptation is not possible. Indeed, the literature finds that in a Cournot IEA game with no adaptation nor leakage, the maximum number of countries that join a coalition is also three (Table 1). The intuition behind this result is as follows. In the absence of adaptation, each country has free riding incentives to reduce emissions because countries' emission strategies are independent. In our paper, adaptation and emissions move in the same direction. Recall from Proposition 1 that adaptation and emissions are strategic complements in the absence of leakages. Hence, this complementarity leaves the free riding incentives unchanged and thus adaptation does not bring in any new mechanism to reduce free riding incentives in this setting. This implies that the maximum number of countries that join an IEA remains unchanged when we introduce adaptation in a world with no leakage. 
Next, we explore whether these results change when countries differ in adaptation costs. We calculate the stability of an agreement numerically because analytical solutions cannot be derived since the equilibrium solutions are implicit. We constrain the set of parameter values such that both the non-negativity of emissions $\left(e_{i}>0\right)$ and no over-adaptation $\left(\omega>a_{i}\right)$ hold. We first select a set of parameter values, and second, we study how sensitive our results are to changes in those values. For the benefit function in equation (2), we choose a combination of $\alpha$ and $\beta$ parameters such that the slope is larger than the intercept of the marginal benefit from emissions, i.e. $\alpha<\beta$. We consider a set of $n=100$ countries where half are low cost countries. We use the set of parameters, $\alpha=2.9$ and $\beta=223$. The damage parameter is $\omega=0.029$ and adaptation costs $c^{L}=44.5$ and $c^{H}=45$, i.e., $c^{L}<c^{H}$. ${ }^{14}$ This case corresponds to Proposition 7.(ii).

The maximum stable coalition size is equal to three in line with the case with symmetry in adaptation cost discussed in Proposition 7.(i). Indeed, Propositions 7.(i). and 7.(ii), contribute to a better understanding of the role of adaptation and the lack of leakage in the success and failure of IEAs. The possibility to adapt does not introduce incentives to reduce the free rider behaviour due to lack of leakage. This result is in contrast with Marrouch \& Ray Chaudhuri (2011) who find that the grand coalition can be an equilibrium outcome with no leakages but in a Stackelberg game.

Our results shed some light on the role of adaptation in changing country incentives to join IEAs. As mentioned before, some argue against placing efforts into adaptation, fearing diminished willingness to join international agreements to reduce emissions. See, for example, the article "Dutch defense against climate change: Adapt" published in The Washington Post in 2009. Contrary to this belief, our results show that the presence of

\footnotetext{
${ }^{14}$ We carry out sensitivity analyses to study the robustness of our main results using simulations. First, we examine the implication of group size asymmetry on coalition stability. To do so, we fix the total number of countries at $n=100$ while we study the effect of variation in group sizes. Our variations consider cases with $n^{L}, n^{H} \in[2,98]$. Our results suggest that the incentive to ratify the treaties are unaffected by the group size asymmetry.
} 
adaptation does not reduce country incentives to join IEAs. While unfortunately we find no evidence that adaptation can encourage coalition formation, at least our results confirm that adaptation does not play a negative role in the incentives to form IEAs in a world with no leakage.

We now turn to the case with leakages, which is a particularly interesting case since leakages enhance interaction among countries. We consider the widely used quadratic damage function (with $\eta=2$ ) as an example of the non-linear case. The previous literature finds that the maximum number of countries that form a stable coalition is two in a world with leakage (first row of Table 1). Next, we analyze how these results change in the presence of adaptation.

We start by analyzing the stability conditions when countries have identical adaptation costs before we turn to cost heterogeneity. We also derive the result with a numerical exercise. As before, our choice of parameter values is: $n=100$ countries, $\alpha=2.9$ and $\beta=223, \omega=0.029$ but with $c=45$. We conduct sensitivity analyses on these parameter values. We summarize our results with identical costs in the Proposition 7.(iii).

Proposition 7.(iii) departs from the baseline scenario without adaptation, where the maximum stable coalition size is two (see Table 1). In contrast, we find stable equilibria where three countries choose to join an IEA. This result implies that the existence of adaptation could enhance the incentives to join the coalition. While an increase in the stable coalition size is an encouraging outcome, yet the puzzle of small coalitions remains in this setting. The intuition behind this result is as follows. With leakages in emissions, a country's response to larger emissions by others is to reduce its own emissions since the best response functions are downward slopping (eqs. (25) and (28)). Moreover, the possibility to adapt makes these best response functions flatter (Benchekroun et al., 2011). This implies a lower willingness to reduce emissions when other countries increase theirs. This willingness yields a higher number of countries interested in joining an IEA relative to the case without adaptation. 
Now that we understand the pure contribution of adaptation to the stability of IEAs, we explore how cost heterogeneity affects participation incentives in a world with carbon leakage. This case corresponds to Proposition 7.(iv). We derive this result using the same set of parameter values as before, except that we include cost heterogeneity where $c^{L}=44.5$ and $c^{H}=45$. We find that the maximum number of countries that could join a coalition is three. While the incentives to participate increase with adaptation, comparing this result to the case of cost symmetry in adaptation, we find that cost heterogeneity does not enhance the incentives to join an IEA. These results are robust to changes in the total number of countries, in environmental damages $(\omega)$ and in benefits from pollution. With these examples, we find that carbon leakage in combination with adaptation increases the incentives to join a coalition while cost heterogeneity leaves the incentives unchanged.

Some might worry that cross-country differences in adaptation costs might weaken the incentives to join an IEA on the basis that the provision of adaptation is a private good. Our results, which are robust to the choice of parameters, show that cross-country differences do not weaken participation incentives. In fact, we find that in some specific cases, we can even obtain cases in which cross-country differences might strengthen IEA participation to the point that any coalition size between three and $n$ can be achieved as a stable outcome, including the grand coalition. Next, we present these cases and discuss the conditions under which cost heterogeneity increases IEA participation compared to the symmetric case.

We choose sets of parameter values that satisfy the following characteristics. One, the number of countries is smaller than before, let's say $n=20$ countries, where 10 are low cost. Two, the parameters in the benefit function satisfy $\alpha=0.1$ and $\beta=1500$ and, three, environmental damages are $\omega=0.0000001$. When these three characteristics hold, we find that any number of countries between three and $n$ could join an IEA with cost heterogeneity $\left(c^{L}=14\right.$ and $\left.c^{H}=14.5\right)$ while no country decides to join with cost homogeneity. ${ }^{15}$ This

\footnotetext{
${ }^{15}$ For example, with the set of parameter values $n=20$ countries, $n_{L}=10, n_{H}=10 \alpha=0.1$ and $\beta=1500$,
} 
result implies that there exists some cases in which any number of countries would participate in an IEA in a world with carbon leakage and cross differences in the cost of adaptation. While these results are sensitive to the choice of parameter values, it is interesting to know that there exist some examples in which a large number of countries would join a coalition. These results vary with the choice of parameter values. For example, we find that as the number of countries $n$ tends to rise, participation tends to decrease. Also, we find that as the marginal damage from emissions increases (as $\omega$ ), the free riding incentives increase and the incentives to join the coalition diminish. We also study the implications of the magnitude of cost difference on this result. In particular, we use the same set of parameters except that we vary $c^{H}$. Our numerical exercise reveals a clear relationship between the stable coalition size and the potential gain from cooperation. ${ }^{16}$ As the potential gains increase so does the equilibrium coalition size, which is a result that is in contrast to the traditional IEA literature (see, for example, Barrett, 1994). Although the magnitude of the cost heterogeneity (the difference between $c^{H}$ and $c^{L}$ ) does not display a monotonic relation with the equilibrium coalition size, small or large heterogeneity can result in small or large stable coalitions. In contrast with the baseline scenario where adaptation is not possible (see Table 1), the above results suggest that leakage and heterogeneity in adaptation costs provide a way to overcome the puzzle of small coalitions.

In this case as well, the worry that cross-country differences in adaptation costs might weaken the incentives to join an IEA are alleviated. Indeed, this result suggests that crosscountry differences might instead strengthen IEA participation. The possibility to encourage participation even with cross-country differences is an optimistic result.

Our Propositions 7.(i). and (ii) have some policy implications. Participation incentives

$\bar{\omega}=0.0000001, c^{L}=14$ and $c^{H}=14.5$ the maximum number of countries that join is 18 . And, with the set of parameter values $n=20$ countries, $n_{L}=10, n_{H}=10 \alpha=0.1$ and $\beta=1500, \omega=0.0000001, c^{L}=14$ and $c^{H}=16$ full cooperation is sustained as an equilibrium outcome.

${ }^{16}$ The potential gain from cooperation is defined as $n^{L}\left[W_{s}^{L}\left(n^{L}, n^{H}\right)-W_{n s}^{L}(0,0)\right]+n^{H}\left[W_{s}^{H}\left(n^{L}, n^{H}\right)-\right.$ $\left.W_{n s}^{H}(0,0)\right]$. 
are not affected when there are no leakages irrespective of cost heterogeneity. This result implies that, in the absence of leakages, policies directed at reducing the cross-country gap in adaptation costs might be ineffective at increasing the success of IEAs.

To sum up, we look again at Table 1. Our most striking result arises when we compare the case without carbon leakage to the case with leakage. In the absence of leakages, adaptation is not potent enough to increase the incentives to participate because of the complementarity between adaptation and emissions. With leakages, however, adaptation introduces new incentives that can counteract the free riding incentives on emissions and in turn increase the incentives to participate in an agreement.

\section{Conclusion and policy implications}

In this paper we examine how adaptation affects countries' incentives to ratify IEAs. In particular, we study the impact of cross-country differences in adaptation costs and the role of leakages on participation incentives. In this setting, our results suggest that adaptation is unsuccessful at encouraging participation without leakages while potentially successful with leakages. Furthermore, we find that cost heterogeneity in adaptation costs could strengthen the incentives to join a coalition when there are leakages among countries.

In our paper, countries' choice of emissions and adaptation are complements without leakages. This means that a country has stronger incentives to emit when the cost of adapting is low. With leakages, however, the strategic relationship depends on the magnitude of adaptation, costs and damages. While this relates to some's fears regarding high pollution as a consequence of low adaptation costs, our results suggest that the possibility to adapt does not necessarily limit a country's incentives to voluntarily reduce emissions within a climate coalition. In fact, we find that the role of adaptation in coalition formation is highly dependent on the the existence of leakages. In fact, we find stronger incentives to join a 
coalition to reduce emissions when countries generate leakages and have the option to adapt.

Our results have relevant implications for policies directed at reducing the gap in adaptation costs among developed and developing countries. For example, the Cancún Adaptation Fund, ${ }^{17}$ established in 2010 to reduce the technological gap that exists between developed (low cost) and developing (high cost) countries. We find that cost heterogeneity in adaptation is associated with higher participation in IEAs. Hence, a policy directed at reducing the cost gap in adaptation must also consider that the incentive to join a coalition might be altered when heterogeneity decreases or ceases to exist.

Our results also have implications for policies directed at regulating leakages. Since our analysis suggests the existence of stronger incentives to join a coalition with leakages, policies directed at reducing the leakage among countries could reduce the incentives to form a coalition to abate emissions. For example, some argue in favor of the Clean Development Mechanism to reduce carbon leakage (see, for example, Kallbekken, 2007). In our setting, such a policy could weaken the incentives to join a coalition.

Our discussion is not intended as criticism against existing international climate policies, such as the Cancún Adaptation Fund or the Clean Development Mechanism. Instead, we draw attention to how such policies might change the incentives to form large coalitions. Our results indicate that heterogeneity among countries encourages coalition formation, and hence, policies directed at reducing these heterogeneities could create barriers for coalition formation.

Finally, we summarize some of the limitations of our study and we make suggestions for further research. First, we assumed that the effect of pollution, $(\omega)$ is identical for all countries. While it is likely that global emissions affect each country differently, we chose to abstract from this heterogeneity and concentrate on the role of cross-country differences in adaptation. An extension could be to make this effect heterogeneous. Another possible

\footnotetext{
${ }^{17}$ More information regarding the Funds is available at https://www.adaptation-fund.org/.
} 
extension is to analyze transfer programs in relationship with the policies discussed above. Despite these limitations, our paper provides a complementary explanation to better understand the incentives to join IEAs. 


\section{References}

Barrett, S. (1994). Self-enforcing international environmental agreements. Oxford Economic Papers, (pp. 878-894).

Benchekroun, H., Marrouch, W., \& Ray Chaudhuri, A. (2011). Adaptation Effectiveness and Free-Riding Incentives in International Environmental Agreements. Discussion Paper 2011-120, Tilburg University, Center for Economic Research.

Breton, M., Sbragia, L., \& Zaccour, G. (2010). A dynamic model for international environmental agreements. Environmental and Resource Economics, 45(1), 25-48.

Buob, S. \& Stephan, G. (2008). Global climate change and the funding of adaptation. Discussion Papers, Universität Bern, Switzerland.

Buob, S. \& Stephan, G. (2011). To mitigate or to adapt: how to confront global climate change. European Journal of Political Economy, 27(1), 1-16.

Carraro, C. \& Siniscalco, D. (1993). Strategies for the international protection of the environment. Journal of Public Economics, 52(3), 309-328.

d'Aspremont, C., Jacquemin, A., Gabszewicz, J. J., \& Weymark, J. A. (1983). On the stability of collusive price leadership. Canadian Journal of Economics, (pp. 17-25).

de Zeeuw, A. (2008). Dynamic effects on the stability of international environmental agreements. Journal of Environmental Economics and Management, 55(2), 163-174.

Ebert, U. \& Welsch, H. (2012). Adaptation and mitigation in global pollution problems: economic impacts of productivity, sensitivity, and adaptive capacity. Environmental and Resource Economics, 52(1), 49-64. 
Eyckmans, J. \& Tulkens, H. (2003). Simulating coalitionally stable burden sharing agreements for the climate change problem. Resource and Energy Economics, 25(4), 299-327.

Finus, M. (2003). Stability and design of international environmental agreements: the case of transboundary pollution. International yearbook of environmental and resource economics, $4,82-158$.

Hoel, M. \& Schneider, K. (1997). Incentives to participate in an international environmental agreement. Environmental and Resource Economics, 9(2), 153-170.

Kallbekken, S. (2007). Why the cdm will reduce carbon leakage. Climate Policy, 7(3), $197-211$.

Kane, S. \& Shogren, J. (2000). Linking adaptation and mitigation in climate change policy. Climatic Change, 45(1), 75-102.

Marrouch, W. \& Ray Chaudhuri, A. (2011). International Environmental Agreements in the Presence of Adaptation. Discussion Paper 2011.35, Fondazione Eni Enrico Mattei.

McGinty, M. (2007). International environmental agreements among asymmetric nations. Oxford Economic Papers, 59(1), 45-62.

Mendelsohn, R. (2000). Efficient adaptation to climate change. Climatic Change, 45(3), $583-600$.

Nkuiya, B. (2012). The effects of the length of the period of commitment on the size of stable international environmental agreements. Dynamic Games and Applications, 2(4), $411-430$.

Nkuiya, B., Marrouch, W., \& Bahel, E. (2014). International environmental agreements under endogenous uncertainty. Journal of Public Economic Theory, forthcoming. 
Onuma, A. \& Arino, Y. (2011). Greenhouse gas emission, mitigation and innovation of adaptation technology in a north-south economy. Environment and Development Economics, 16(6), 639-656.

Parry, M. L. (2007). Climate Change 200\%: impacts, adaptation and vulnerability: contribution of Working Group II to the fourth assessment report of the Intergovernmental Panel on Climate Change, volume 4. Cambridge University Press.

Petrosjan, L. \& Zaccour, G. (2003). Time-consistent shapley value allocation of pollution cost reduction. Journal of Economic Dynamics and Control, 27(3), 381-398.

Rubio, S. J. \& Ulph, A. (2006). Self-enforcing international environmental agreements revisited. Oxford Economic Papers, 58(2), 233-263.

Rubio, S. J. \& Ulph, A. (2007). An infinite-horizon model of dynamic membership of international environmental agreements. Journal of Environmental Economics and Management, $54(3), 296-310$.

Samuelson, P. A. (1954). The pure theory of public expenditure. The Review of Economics and Statistics, 36(4), 387-389.

Zehaie, F. (2009). The timing and strategic role of self-protection. Environmental and Resource Economics, 44(3), 337-350. 


\section{Appendix}

\section{Proof of proposition 2}

From total emissions in the polar cases in equations (20) and (21), we derive:

$$
E_{n}-E_{c}=n(n-1) \frac{\beta \omega-\alpha\left(\frac{n^{H}}{c^{H}}+\frac{n^{L}}{c^{L}}\right)}{\left(\beta-\left(\frac{n^{H}}{c^{H}}+\frac{n^{L}}{c^{L}}\right)\right)\left(\beta-n\left(\frac{n^{H}}{c^{H}}+\frac{n^{L}}{c^{L}}\right)\right)} .
$$

Assume by contradiction that $E_{n} \leq E_{c}$. In this case, given the existence assumptions 22 and 23, equation (41) implies that:

$$
\omega \leq \frac{\alpha}{\beta}\left(\frac{n^{H}}{c^{H}}+\frac{n^{L}}{c^{L}}\right)
$$

Rearranging (42) leads us to

$$
a_{n}^{L}>\frac{1}{c^{L}} \frac{n \omega}{\left(\frac{n^{H}}{c^{H}}+\frac{n^{L}}{c^{L}}\right)} .
$$

Combining this relation with the assumption that no over adaptation is possible $\left(i . e ., a_{n}^{L}<\right.$

$\omega)$, we get $\omega>\frac{1}{c^{L}} \frac{n \omega}{\left(\frac{n^{H}}{c^{H}}+\frac{n^{L}}{c^{L}}\right)}$. This implies that $E_{n} \leq E_{c}$ holds if and only if $c^{L}>c^{H}$. Since this condition is a contradiction with $c^{H}>c^{L}$, we necessarily have $E_{n}>E_{c}$.

\section{Proof of proposition 3}

We define $l(E) \equiv \eta(\beta E-n \alpha)$ as a function given by the left-hand sides of both equations (12) and (18). We also denote $h(E) \equiv\left(E_{n}\right)^{\eta-1}\left[-n \eta \omega+\left(\frac{n^{L}}{c^{L}}+\frac{n^{H}}{c^{H}}\right)\left(E_{n}\right)^{\eta}\right]$ as the right-hand side of $(12)$ and $g(E) \equiv n\left(E_{c}\right)^{\eta-1}\left[-n \eta \omega+\left(\frac{n^{L}}{c^{L}}+\frac{n^{H}}{c^{H}}\right)\left(E_{c}\right)^{\eta}\right]$ as the right-hand side of (18). We represent these functions in Figure 1, with $\eta>1$, where $E_{n}$ is defined by the intersection between $l(E)$ and $h(E)$ while $E_{c}$ is given by the intersection between $l(E)$ and $g(E)$. From the benefit function in (2), total emissions must be smaller than $B \equiv n \alpha / \beta$, which is true for both $E_{c}$ and $E_{n}$ as illustrated in Figure 1. Then, we necessary have $E_{c}<E_{n}$. For adaptation, since $E_{n}>E_{c}$, by conditions (9) and (17), the result follows. 


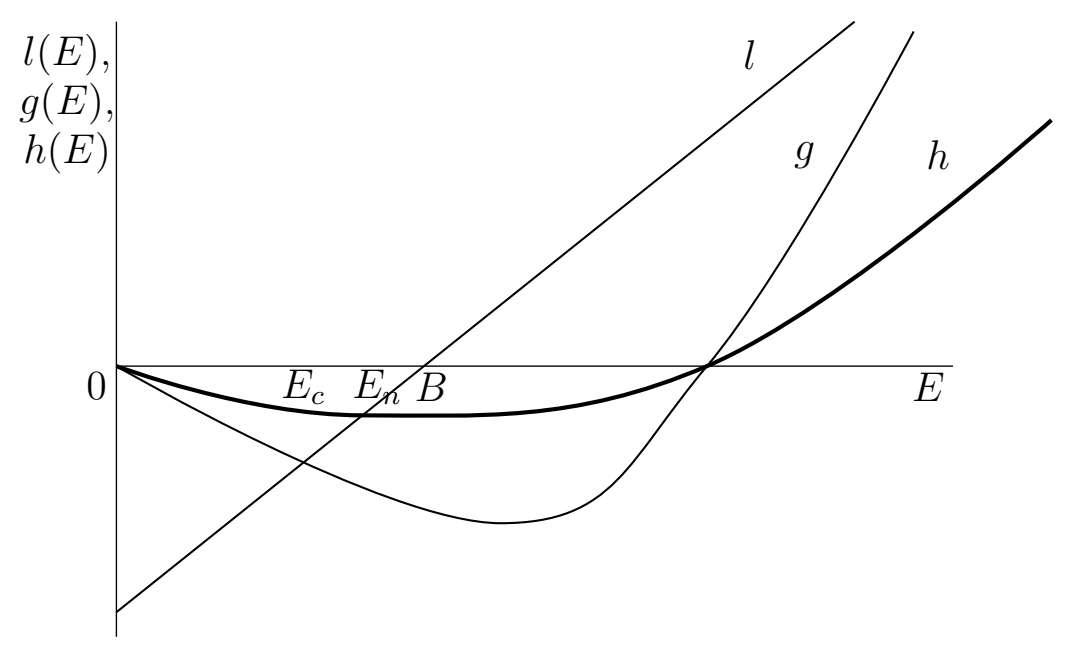

Figure 1: The comparison between $E_{n}$ and $E_{c}$.

\section{Proof of proposition 7.(i)}

Consider countries with a linear damage function $(\eta=1)$ and identical adaptation costs. Then, the stability function is $\phi(k)=W_{s}(k)-W_{n s}(k-1)$. We re-write this stability condition as:

$$
\phi(k)=\frac{(k-1)(n \alpha-c \beta \omega)^{2}}{2 \beta\left(\left(3 k-k^{2}-n+c \beta-2\right)\left(k-k^{2}-n+c \beta\right)\right)^{2}} \Omega(k, n),
$$

where $\Omega(k, n)=(3-k)(c \beta)^{2}+2\left(k^{3}-4 k^{2}+(n+3) k-n-2\right)(c \beta)-k^{5}+5 k^{4}-(2 n+7) k^{3}+$ $(4 n+3) k^{2}+\left(2 n-n^{2}\right) k-n^{2} . \Omega(k, n)$ is a second degree polynomial (in $\left.c \beta\right)$ with the following roots:

$$
\begin{aligned}
& \beta_{1 s}=\frac{1}{k-3}\left(3 k-n+\sqrt{\Delta}+k n-4 k^{2}+k^{3}-2\right) \\
& \beta_{2 s}=\frac{1}{k-3}\left(3 k-n-\sqrt{\Delta}+k n-4 k^{2}+k^{3}-2\right),
\end{aligned}
$$

where $\Delta=-12 k+7 n+k n^{2}+4 k^{2} n-17 k n+16 k^{2}-4 k^{3}+n^{2}+4$.

Any coalition of size $k \geq 4$ is internally stable if and only if $\phi(k) \geq 0$. Since all terms multiplying $\Omega(k, n)$ are positive, this condition holds when $\Omega(k, n) \geq 0$. This inequality holds if and only if $c \beta \in\left[\beta_{2 s}, \beta_{1 s}\right]$. In addition, we find that $\beta_{2 s}<\beta_{1 s}<n^{2}$. These results combined with the existence assumption (23) suggest that any coalition of size $k \geq 4$ cannot 
be internally stable.

It remains to show that a coalition of size $k=3$ may be stable. By setting $k=3$, we get $\Omega(3, n)=4 c \beta(n-1)-\left(3 n^{2}+13 n\right)$. Since $\Omega(3, n)$ is positive when $c \beta \geq\left(3 n^{2}+13 n\right) / 4(n-1)$, we find that the maximum number of countries that can join a coalition is equal to three when this condition holds. 